\title{
ON THE LONG WALLS OF ATHENS.
}

According to the view which has long held the field and is still the most widely accepted, the Long Walls which the Athenians constructed in the fifth century to connect their town and harbour were three in number, viz., two outer walls extending respectively to the northern and southern sections of the harbour fortifications, and an intermediate wall running longitudinally in the gap between the outer pair. ${ }^{1}$

This theory rests on evidence which prima facie appears very strong. Harpocration distinctly enumerates three walls, known respectively as the Northern, the Southern or Middle, and the Phaleric one, and in support of his statement he quotes a passage from Aristophanes, in which three walls are likewise mentioned. ${ }^{2}$ The same number of walls also seems to be implied in a passage of Thucydides, where mention is made, firstly, of a Phaleric wall, and secondly, of 'Long Walls,' 3 which should presumably be identified with the Northern and Southern walls of Harpocration, so as to make three walls in all. A triple line of fortifications is also suggested by the current

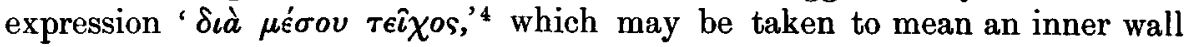
running between an outer pair.

On the other hand there are numerous passages in ancient texts which make mention of two walls, and two only. ${ }^{5}$ The usual explanation of this discrepancy is that during or after the Peloponnesian War one of the three walls (the Phaleric one) was demolished or neglected, and that from the fourth century onward only the Northern and Middle ones remained. ${ }^{6}$ This view is commended by the fact that all the texts referring to a double

1 Leake, Topography of Athens i. p. 426 ; Curtius, Stadtgeschichte von Athen, pp. 111-2; Wachsmuth, Stadt Athen im Allertum i. pp. 328-9; Kaupert, Monalsberichte der Berliner Akademie 1879, pp. 628-38; Judeich, Topographie von Athen, pp. 144-8; Grote, History of Greece (10th ed.), iv. pp. 505-6; Ed. Meyer, Gcschichte des Altertums, iv. p. 36 ; Busolt, Griechisehe Geschichte, iii. p. 310.

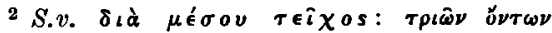

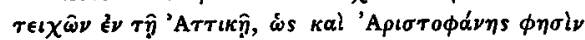

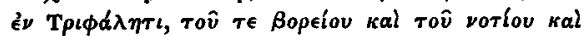

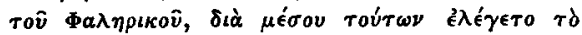

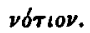

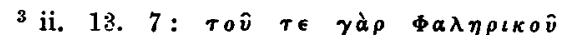

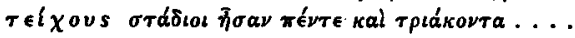

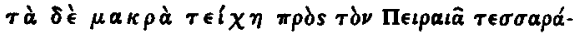

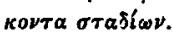

4 Antiphon fr. 37 (ed. Blass) ; Cratinus ap. Plutarch, De Gloria Atheniensium, p. $351 \mathrm{~A}$; Plutarch, Pericles, ch. $13 \S 5$; Schol. ad Plat. Gorgias, $455 \mathrm{E}$; Harpocration s.v. (see n. 2 above).

5 The passages in question are enumerated in Leake, pp. 422-3.

6 Leake, pp. 426-7, followed by most later writers. 
line of walls belong to the fourth or later centuries. But an alternative theory has been set up by Prof. E. A. Gardner, who maintains that there never were more than two walls, ${ }^{7}$ and a closer inspection of the evidence may show that this solution of the problem is the more likely.

In the first place, considerations of common sense tell against a triple line of fortifications. If a double line was quite sufficient, as the event proved it to be, why did the Athenians ever trouble to build three walls? In answer to this it has been suggested that the original scheme of fortifications comprised only the Northern and the Phaleric walls, and that an intermediate wall was subsequently constructed in order to strengthen the defences on the maritime side. ${ }^{8}$ Now this hypothesis is plausible enough from the standpoint of those scholars who locate Phalerum near Cape Colias at the east end of the Phaleric Bay and consequently represent the Phaleric wall as meeting the coast at a considerable distance from the Northern wall, which undoubtedly ran to Piraeus. ${ }^{9}$ A couple of walls built on such a plan would certainly need to be supplemented by an intermediate fortification, for the wide expanse of Phalerum Bay would otherwise have been left defenceless. But, to say nothing of the obvious folly of the Athenians in leaving their sea front unguarded until by a happy afterthought they built the necessary third wall, the location of Phalerum at the east end of the bay is almost certainly a mistaken one, and the Phaleric wall cannot therefore have taken this direction. ${ }^{10}$

If on the other hand we follow Leake and most modern authorities in placing Phalerum at the west end or centre of the bay and in giving the Phaleric wall an abutment on the Piraeus fortifications, the raison d'etre of the Middle wall disappears. It would not materially strengthen the defences between harbour and city, nor yet would it reduce the length of lines requiring to be held to any appreciable extent. A priori, therefore, the existence of a third wall is not at all probable.

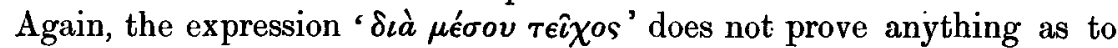
the number of the Long Walls. It may be taken in quite a different sense from that which is adopted by Harpocration and most modern critics. In a

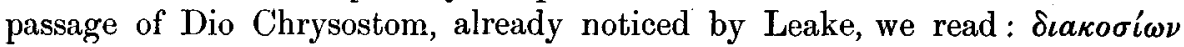

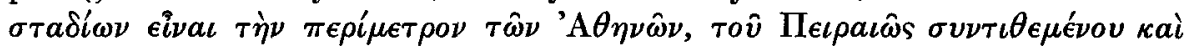
$\tau \hat{\omega} \nu \delta \iota \grave{a} \mu \epsilon \in \sigma o \nu \tau \epsilon \iota \chi \hat{\omega} \nu .{ }^{11}$ The plural form $\tau \epsilon \iota \chi \chi^{\hat{\omega} \nu}$ suggests that the reference is not to a single piece of masonry, but to a whole complex, and the general

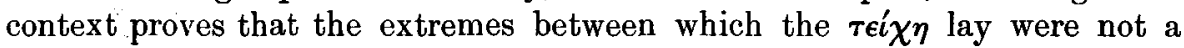

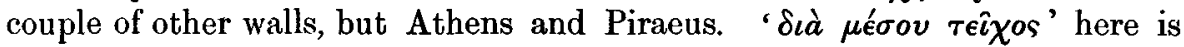
nothing but a synonym for the Long Walls as a whole.

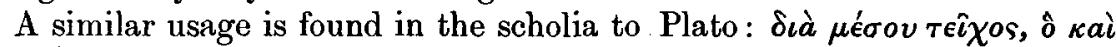

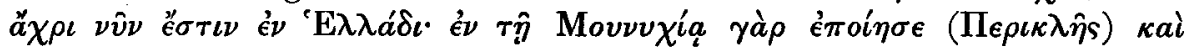

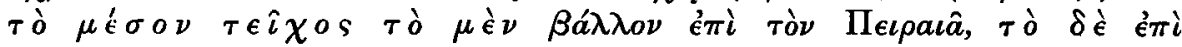

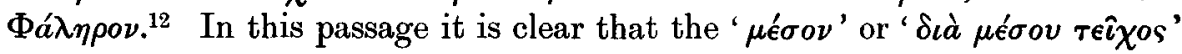

` Ancient Athens, pp. 68-71.

8 Leake, p. 427.

So Curtius, p. 110 ; Kaupert, pp. 632-4. H.S.-VOI. XXXIV.
10 Gardner, pp. 57-8, 562 ; Judeich, p. 148 .

11 Or. 6 p. 96 (ed. Dindorf).

12 Gorgias, $455 \mathrm{E}$. 
consists of two different fortifications. ${ }^{13}$ Probably, as in the previous quotation, it stands for the Long Walls taken in their entirety; in any case it does not refer to a single wall intermediate between two outer lines.

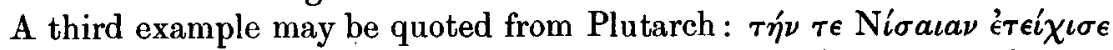

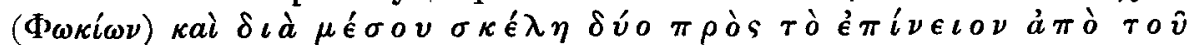
ă $\sigma \tau \in \sigma_{S} \epsilon^{\prime} \nu \epsilon \in \beta a \lambda \epsilon .{ }^{14}$ The term ' $\sigma \kappa \hat{\epsilon} \lambda \eta$ ' obviously denotes a pair of walls, and the rest of the sentence says in so many words that the termini intra quos were the harbour and city (of Megara, in this case).

There can be no doubt, then, that Harpocration was wrong in his explanation of the words ' $\delta \iota \grave{a} \mu \epsilon$ éov $\tau \epsilon \hat{\imath} \chi o s$.' But this is not the only point on which his authority can be impugned. The words which he quotes from

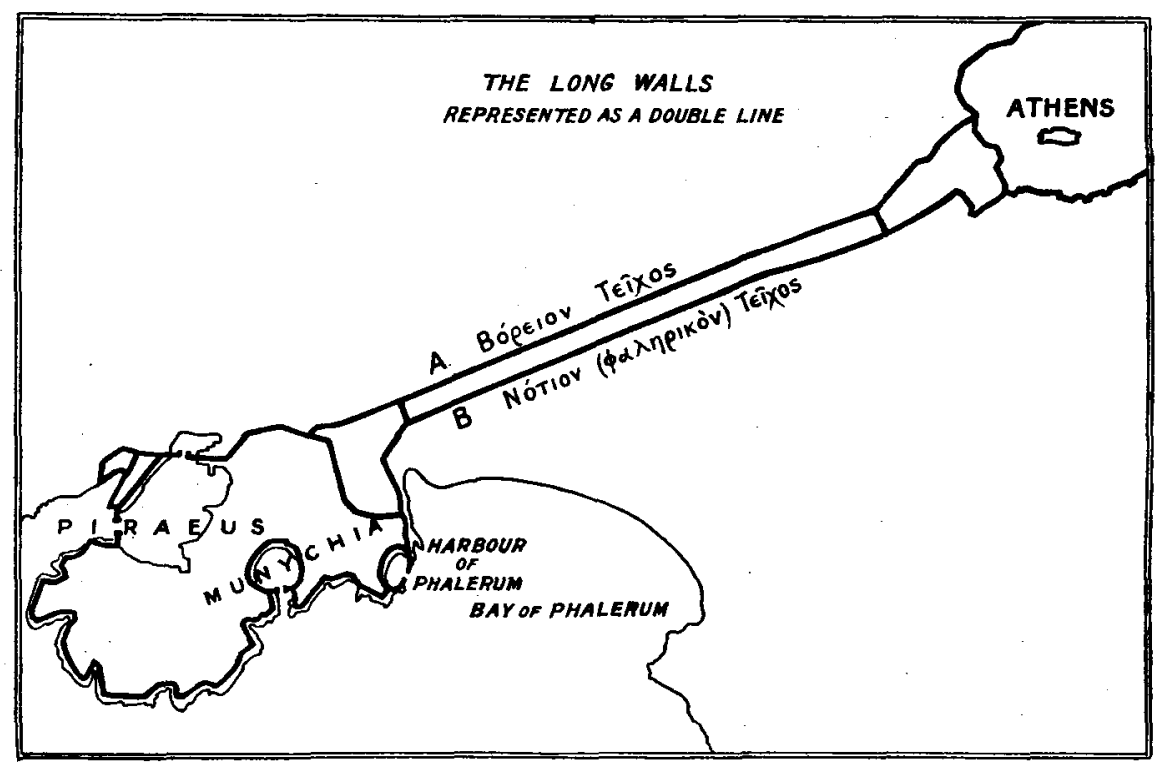

After BA Gardner. Ancient Athons)

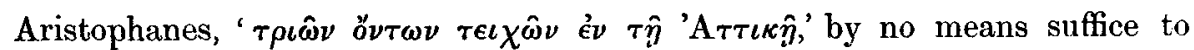
prove the existence of three Long Walls, for it is not at all clear that the reference is to the Long Walls rather than to any other walls in Attica which might be considered as a trio. ${ }^{15}$ And again, Harpocration's own

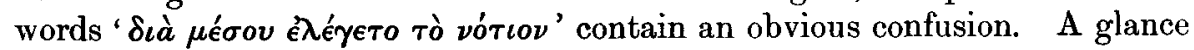
at the map will show that if and so long as three walls existed, the epithet ' 'ó $\iota$ ' ' must have belonged not to the Middle but to the Phaleric line. It is, of course, possible that after the demolition of the Phaleric wall the 'Middle' wall should have usurped the name of Southern, but this could only be by virtue of its ceasing to be a ' middle ' wall. If Harpocration could equate

13 Leake (p. 431, 21. 4) supposes that the scholiast implied a single. wall connecting Piraeus and Phalerum. But the phrase " $\tau \dot{\delta}$

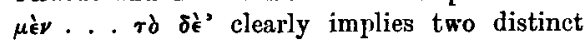

walls.

14 Phocion, ch. 15.

15 Gardner, p. 69, n. 2. 
' middle' and 'southern' as if the two had at all times been convertible terms, it is plain that the true history of the Long Walls was not properly understood by him. Altogether, Harpocration's statement as to the Long Walls cannot be regarded as authoritative.

There remains the passage in Thucydides. The key words here are

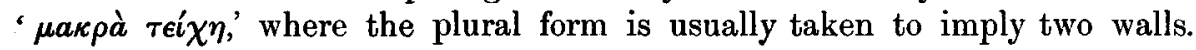
This inference is not conclusive, for a good many Greek authors, ${ }^{16}$ including Thucydides himself, ${ }^{17}$ use ' $\tau \epsilon i ́$ ' $\chi$ ' to designate a single wall. In the present case the plural form could be applied all the more readily to a single wall if we suppose that the wall had a double face, so that it might be regarded as a couple of walls set back to back. ${ }^{18}$

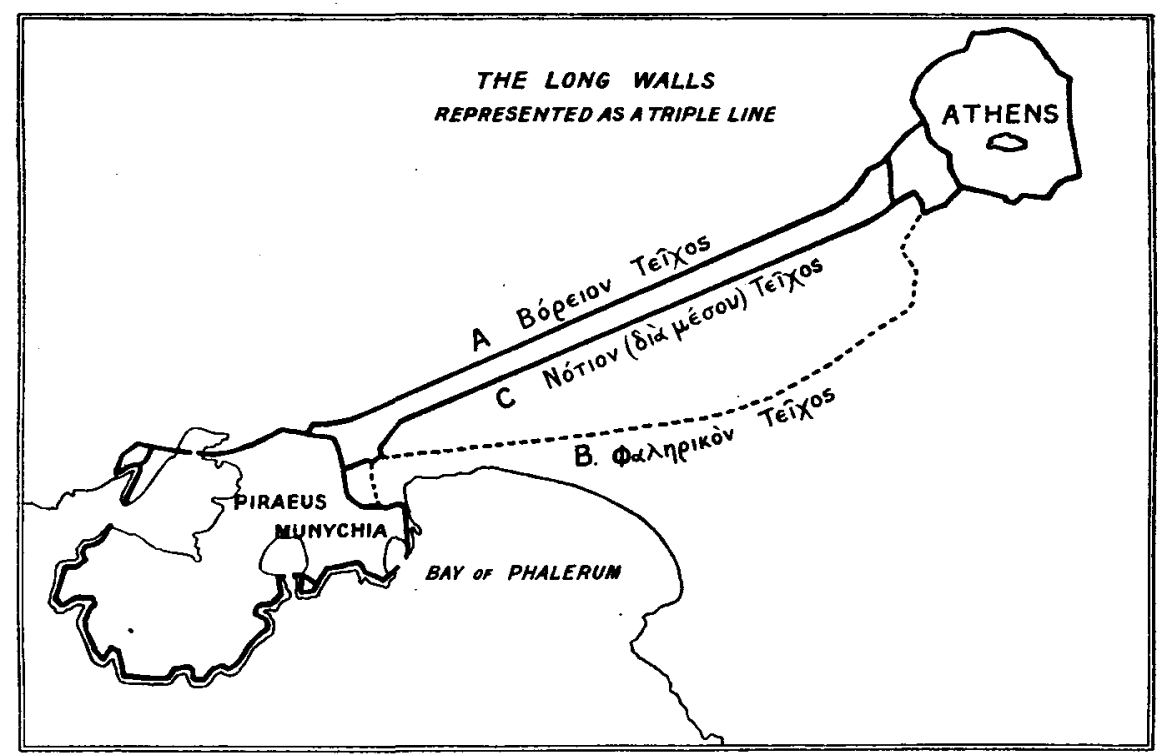

(After Judeich, Sopographicic von Athen)

So far, then, Thucydides' language is ambiguous. But in an adjacent passage he supplies us with a crux. In the sentence previous to the one quoted above we read $\epsilon^{\sigma} \sigma \tau \iota \delta \dot{\epsilon} a \dot{v} \tau o \hat{v}$ (of the ring wall of Athens) $\hat{o} a \dot{a} \phi v \lambda a \kappa \tau \dot{\nu} \nu$

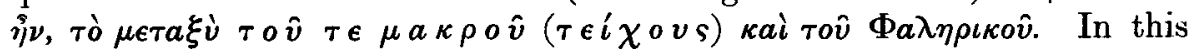

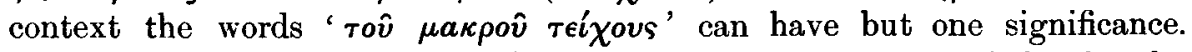
They cannot be taken to stand for the Long Walls as a whole, for the Phaleric wall, which was an integral part of the system, is mentioned as

${ }^{16}$ Numerous instances are given in Stephanus, s.v.

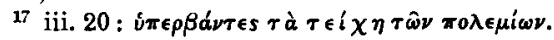
This refers to the single line of walls built by the Peloponnesians round Plataea. Cf. also our expression 'the Walls' (not 'Wall ') of Chester. York, Jericho, etc.

The use of the plural form in all these cases shows that it is quite natural to think of a wall as an aggregate of its sections.

18 On this point see Gardner, p. 70, and n. 22 below.

The investment wall of the Peloponnesians at Plataea, referred to in the previous note, was likewise built with two faces. 


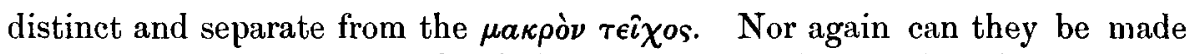
to refer to the Northern and Middle walls regarded as an individual entity. If any two walls out of three could be selected as the Long Walls par excellence, the choice must necessarily fall on the Northern and Phaleric walls, for these were ex hypothesi the original pair, whereas the Middle wall

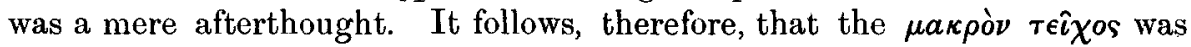
a single wall, viz. the Northern one, and that Thucydides only mentions this and the Phaleric wall, i.e. two walls in all.

So much, then, for the texts which are usually quoted in the discussion of the present problem. In addition to these account should be taken of a passage in Andocides, ${ }^{19}$ which relates the construction of the Long Walls section by section, and in so doing makes mention of two lines only, a 'northern' and a 'southern' one. The relevance of this passage to the question at issue is not usually admitted, because the speech in which it is contained was not delivered until 392-1 B.C., and the orator is supposed to be referring to those walls only which were extant at the time of his speaking. No conclusion, it is argued, can be drawn in this case as to the total number of the walls as they stood in the days of Pericles. But this explanation of Andocides' words is unsatisfactory. As the whole of the surrounding context shows, the purpose of the orator in mentioning the Long Walls was to illustrate by them the prosperity of the times at which they were built. With this object in view Andocides had every reason to make the most of the Walls, or even to exaggerate the scale on which they were built. If therefore only tro walls are mentioned by him, it is a fairly safe inference that he only knew of two. And this is as much as saying that there were only two, for Andocides himself and many of his audience must have seen the Walls as they stood at the outset of the Peloponnesian War, when all the lines were certainly still in good repair, and it is impossible that he should have made a mistake as to their original number.

A closer inspection of the evidence thus tends to show that the Long Walls from beginning to end were only two in number. The Middle wall never existed: there were only a Northern and a Southern or Phaleric line.

If the above reasoning is accepted as correct, a new problem arises. From the previously quoted passage of Andocides, as also from other texts, ${ }^{20}$ it appears that the Iong Walls were not completed simultaneously, but that the Southern wall remained unfinished for some considerable time after the rest of the work had been accomplished. Now if there had been three walls

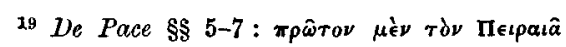

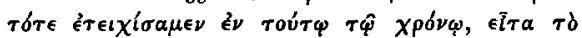

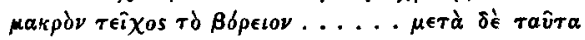

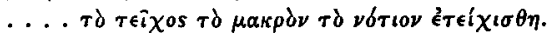

This passage is repeated verbatim in Aeschines, De Falsa Legatione, $\$ \$ 173-4$.

20 See Plutarch, De Gloria Atheniensium, 8 p. 351 , where it is mentioned that a delay took place in the completion of the walls.

The above-quoted passage from Thucydides points to the same conclusion. If the term 'Long Wall' (or 'Walls') could be specially appropriated by him for the Northern as against the Phaleric wall, it may he inferred that the two walls were not built simultaneously, but that the Northern wall came first.

The chronology of Andocides is confused in its details, but he is perfectly explicit about the Long Walls being built in successive stages. 
all told, a delay in erecting one of these would have been a matter of no great importance, for the remaining two lines would provide a fairly complete set of defences in themselves. But if there never were more than two walls, it follows that one of them (the Northern wall) stood in isolation for a term of years. And this at first sight appears absurd, for a single wall extending through some five miles of open and undefended country would be liable to attack on both sides at once, and thus would seem to be quite untenable, until the companion $\sigma \kappa e ́$ os was completed so as to secure its rear.

It must be remembered, however, that at the time when the Long Walls were built Greek siegecraft was still in its infancy, and artillery in particular was conspicuous by its inefficiency or total absence. ${ }^{21}$ Under these conditions a fore-and-aft attack would not necessarily be more formidable than an ordinary frontal assault, and a single stout wall with a double face ${ }^{22}$ might after all be quite strong enough for its purpose. It should further be borne in mind that the cost of a Long Wall was considerable, ${ }^{23}$ and that at the time when these fortifications were being carried out the Athenians were also spending, not to say squandering, money on the Acropolis and other sites. It thus becomes more easy to understand that they should not have pressed the work on the Long Walls to a speedy completion, but should have made shift for a while with a single $\sigma \kappa \hat{\lambda} \lambda o s,{ }^{24}$

At the same time there can be no doubt that a pendant to the North wall formed part of the original scheme of fortifications, ${ }^{25}$ and the construction cf the second $\sigma \kappa \hat{k} \lambda$ os was not abrogated but merely adjourned. The eventual completion of the Southern wall is referred by Andocides ${ }^{26}$ to the period following upon the Second Peloponnesian War and the Thirty Years' Peace (445 B.C.), and it may well be brought into causal connexion with these events. Previous to the campaigns of $447-6$ B.c. the Athenians still had confidence in their land army, and in 457 B.c. they defended Attica by invading Boeotia. At this time, therefore, the Long Walls were not the one and only link between town and harbour, and there was no urgent necessity for a double line of fortifications. But in the ensuing war the Athenian field force turned out to be sadly inefficient, and Attica was left without defence

21 Witness the ludicrous failure of the Peloponnesian League in its attempt to storm the tiny town of Plataea (Thuc. ii. 75 sqq.).

22 If we accept the view that beside the Phaleric wall there was only one other, we must also hold that this second wall was double-

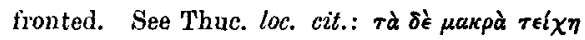

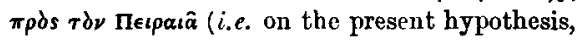

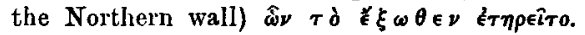
These words imply the existence of an inner as well as an outer face.

${ }^{23}$ In addition to the masonry of the wall the laying of the foundations was an expensive business. It required a special act of generosity on the part of Cimon to fill in the marshy tracts between Athens and the seaboard.
(Plutarch, Cimun, ch. 13.)

24 A further argument might be drawn from Thucydides' description of the Athenian attack upon the Long Walls of Megara in 424 B.c. (iv. 66-9). In this account we read of one wall only being carried by the Athenians, and of one wall serving as an abutment for the lines of cireumvallation drawn round the harbour of Megara. But it is conceivable, though not probable, that Thucydides should have used ' $\tau \in \hat{\imath} \chi$ os' in the singular form to denote a pair of walls.

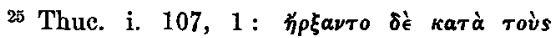

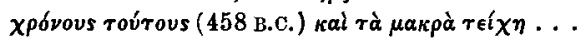

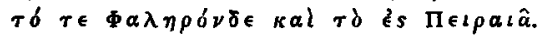

26 De Pace, $\$ 5,6$. 
against invasion. Henceforth it was clear that in the event of a new Peloponnesian War the countryside would have to be abandoned completely, and that the Athenians must put all their trust in stone. Under these conditions it was of course wise to make assurance doubly sure, and it is no matter for wonder that the second line of walls should now have been taken seriously in hand. ${ }^{27}$ But once the second wall had been completed, the connexion between Athens and Piraeus was, humanly speaking, impregnable; and, as has been argued above, there is no sufficient reason to suppose that the number of walls was ever raised to three.

M. O. B. Caspari.

27 It might also be suggested that by building a second wall at some little distance from the first the Athenians also intended to provide a protected camping ground for refugees from the countryside, for which purpose the intermediate area between the two walls would have served admirably. But Thucydides, who records that the homeless folk squatted on every open space and on the Long Walls themselves, does not mention any settlements in between the Walls (ii. 17, 3).

In favour of such settlements Leake quotes

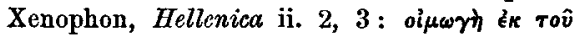

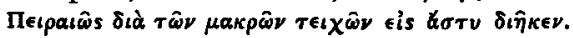
But these words prove nothing. 